\title{
A prospective cohort study of maternal body mass index and maternal and neonatal outcomes in Fiji
}

Kirsten Black ( $\square$ kirsten.black@sydney.edu.au )

University of Sydney Sydney Medical School https://orcid.org/0000-0003-0030-2431

\section{Jyotishna Mudaliar}

Contractor for Murdoch Childrens Research Institute

\section{Pushpa Nusair}

Fiji National University College of Medicine Nursing and Health Sciences

\section{lan Rouse}

Monash University

\section{Research article}

Keywords: Obesity, pregnancy, preconception, BMI, contraception

Posted Date: October 14th, 2019

DOI: https://doi.org/10.21203/rs.2.16020/v1

License: (c) (7) This work is licensed under a Creative Commons Attribution 4.0 International License. Read Full License 


\section{Abstract}

Background: Maternal obesity is highly prevalent in Fiji and the perinatal and long-term consequences are likely to be significant. We investigated the relationship between maternal body mass index and maternal and neonatal outcomes and birth weight centiles in Fijian women. Aims: We sought to use the Intergrowth 21 st (IG21) standard to record the proportion of babies born over the 90 th centile and to examine the association of other maternal and neonatal outcomes with normal weight, overweight and obesity amongst women presenting for antenatal care at the Colonial War Memorial Hospital in Fiji. Methods: From January 2014 - December 2015 we undertook a prospective cohort study that used a structured questionnaire to collect data on women presenting for antenatal care. Body weight was recorded at the booking visit and adjusted to estimated pre-pregnancy bodyweight based on gestation at booking. Midwives collected follow up data regarding the outcomes of these pregnancies and we used the IG21 standard to estimate birthweight centiles. Results: Of the 1397 records, 79 women were underweight and were excluded for detailed analysis. For the remaining 1318 cases detailed pregnancy and follow-up data were available. Compared to normal weight women overweight women were older, parous and were more likely to have pregnancy-related hypertension and were more likely to have an induction of labour. A sixth $(n=224 ; 16.7 \%)$ of the babies were above the 90 th centile of birthweight according to IG21 standard and as maternal BMI class increased, the odds of the baby's birthweight being $>90$ th centile increased. Compared to normal weight women, women with class II or II obesity were three times more likely to have a baby over the 90 th centile (AOR 3.053; Cl 1.907-4.889). Conclusions: A significant proportion of babies born in Fiji are large for gestational age which predisposes them to long term adverse metabolic health outcomes. Addressing maternal obesity before pregnancy is going to be key if Fiji is to curb the growing trend in child and adult obesity and metabolic disease in later life.

\section{Background}

Rates of obesity among women of reproductive age has been rising across all regions of the globe ${ }^{1}$, but Pacific Island nations have some of the highest rates in the world. ${ }^{2}$ Obesity, based on the body mass index (BMI) amongst Fijian women rose between 1980 and 2011 from $30.1 \%$ to $52.9 \%$ in native Fijian i-Taukei women and from $13.2 \%$ to $26.6 \%$ in Fijian Indian women. ${ }^{3}$ The global burden of disease study attributes this largely to dietary risk factors and lack of exercise. ${ }^{4}$ Fijians have moved away from traditional food and food collection methods towards convenience packed foods such as juice, soft drink, crackers, noodles and fried foods.

During pregnancy, maternal obesity has been related to several obstetric and fetal complications, such as hypertensive disorders, caesarean section, gestational diabetes mellitus, congenital anomalies, preterm delivery, fetal macrosomia (with possible birth injury), and unexplained stillbirths. ${ }^{5-8}$ Beyond pregnancy, obese women are at increased risk of type 2 diabetes and cardiovascular disease and their children have an increased risk of obesity in childhood and metabolic disease later in life. ${ }^{9}$ A meta-analysis using 66 studies from 26 countries found that birth weight (>4,000 g) was associated with increased risk of overweight $(\mathrm{OR}=1.66 ; 95 \% \mathrm{Cl} 1.55-1.77)$ later in life. ${ }^{10}$ This cycle of obesity is already evident with $16.1 \%$ of boys under 20 and $31.8 \%$ of girls in Fiji classified in 2013 as overweight or obese. ${ }^{11}$

In this study we sought to examine the association between maternal body mass index (BMI) and key maternal and neonatal outcomes with a particular focus on the relationship between maternal BMI and babies born large for gestational age. For newborns weight we applied the Intergrowth 21 standard $^{12}$ which was obtained from a cohort of 
healthy, well nourished, pregnant women from eight geographically diverse populations who were assessed as low risk for adverse maternal and perinatal outcomes. Experts have argued that applying this standard in place of reference charts will better identify infants at greatest risk and more clearly identify those that are largest for gestational age at birth. ${ }^{13}$

\section{Methods}

A prospective cohort study was conducted at the Colonial War Memorial Hospital (CWMH) Antenatal Clinic in Suva between 1st May 2014 and 31st December 2015. The sample size was based on the known population of reproductive age women living in the Central Division of Fiji and on the sampling required to ensure a representative sample of the three main ethnicity groups; I-Taukei, Fijians of Indian Origin and Fijians of other origins. The ideal calculated sample size was 1116 women of childbearing age. We over sampled to ensure we had adequate numbers to allow for estimation of the key delivery outcomes.

All women pregnant with a single fetus attending the Antenatal Clinic for their first booking visit and who selfidentified as Fijian were invited to participate in the study through a participant information statement.

After consenting to participate, women were asked to complete a questionnaire which asked about their demographic information including ethnicity. As stated above the Fiji population includes three main ethnicities, indigenous population known as the i-Taukei, Fijians of Indian decent, and Fijians of other decent. We asked about their medical conditions, their reproductive history, details of the current pregnancy, their knowledge of family planning and their fertility preferences. Women consented to follow-up of their medical records for the details of antenatal care and complications, and maternal and neonatal delivery outcomes and complications. This information was collected on a structured data collection form.

The body weight of the women was adjusted according to the gestation week of first presentation using standards recommended for body weight gain women for normal or overweight women. Weight gain to 10 weeks gestation was assumed as zero. For the remainder of the pregnancy weight gain for normal weight women was estimated at $450 \mathrm{~g}$ per week and for overweight and obese was estimated as $300 \mathrm{~g}$ per week. After adjusting the bodyweight, a prepregnancy BMI was calculated using the adjusted weight and measured height. Body mass index (BMI) was calculated as weight in kilograms divided by the square of height in meters. We used the WHO categories of Body Mass Index (BMI); less than 18.5 (underweight); 18.5 to 24.9 (normal weight); 25 to 29.9 (overweight) and 30 and over (obese). ${ }^{14}$ The obese categories were further defined as obese class I (BMI 30.0-34.9); obese class II (BMI 35.0-39.9) and obese class III (BMI above 40).

In this study we used the INTERGROWTH-21st (IG 21) standard to document birthweight percentiles of the babies delivered. The birthweight centiles were calculated for 1291 cases where the estimated gestation at birth was between 168 and 300 days. $^{12}$ Estimated due date was calculated using LMP in $74 \%$ of cases and on clinical dating in $26 \%$ of cases. 
All the data were analysed using SPSS version 25. Simple frequencies, means and crosstabulations were used with ttests and Chi Square analysis applied. Binary Logistic regression was used to calculate Odds Ratios for the categories of BMI which were adjusted for age, parity and hypertension and diabetes in pregnancy. Normal weight was used as the comparator so the cases of maternal underweight $(n=79)$ were not included in this study. This study was approved by the Fiji National University, College of Medicine, Nursing and Health Sciences Health Research Ethics committee and the Fiji Ministry of Health and Medical Services National Health Research and Ethics Committee.

\section{Results}

Of the 2203 participants, complete data on demographic factors, body mass index and pregnancy outcomes were available on 1397. Seventy-nine of these had a recorded BMI as underweight and were excluded from the detailed analysis leaving 1318 participants. Estimated due date (EDD) was calculated from the last menstrual period (LMP) in $74 \%$ of the cases and from clinical estimates in the other $26 \%$.

Most women (73\%) reported their ethnicity as indigenous (iTaukei) and most (61\%) were presenting for their first or second pregnancies. Over a quarter of women (28.6\%) were overweight and $36.6 \%$ were obese. Selected demographics of the study population are included in Table 1.

The maternal factors associated with overweight and obesity compared to normal weight are documented in Table 2 with associations with age, parity and hypertension being significant. Screening for pre-existing diabetes occurred in 566 women (42.9\%) and for gestational diabetes in 1014 (76.9\%). Diabetes (both preexisting and gestational) as a complication of pregnancy was not significantly associated with maternal BMI.

The relationship between delivery outcomes and BMI are documented in Table 3 with overweight and obese women more likely to have a preterm delivery and be delivered following induction of labour. There were five cases of shoulder dystocia (not tabled) with two in babies over the $90^{\text {th }}$ centile and three in babies under. Specific neonatal complications such as respiratory distress and neonatal hypogylcaemia were not captured.

A sixth of all babies were over the $90^{\text {th }}$ centile birthweight for their gestation $(n=224 ; 16.9 \%)$. The relationship between neonatal outcomes and maternal BMI are documented in Table 4 with overweight and obese women more likely to have babies above $4000 \mathrm{~g}$ or above the $90^{\text {th }}$ centile. In comparison, normal weight mothers were more likely to have babies whose birthweight was below the $10^{\text {th }}$ centile.

\section{Discussion}

This study found that maternal overweight and obesity is prevalent in Fiji and is associated with increased risk of induction of labor and large for gestational age and macrosomia. Using the IG 21 standard around one sixth of babies born were LGA and the adjusted risk of birthweight over the $90^{\text {th }}$ centile for gestation was 3 times higher in the severe or morbidly obese group. These data confirm and outstrip other groups' findings ${ }^{15,16}$ that have concluded that obese women have an OR ranging between 1.5 and 2.2 of delivering large for date infants, even after controlling for maternal diabetes. 
Using the IG-21 data has provided Fiji with growth centiles across all gestations from 26 weeks when previously only the WHO infant centile charts were used to document newborn weights at term. IG21 thus provides the opportunity to recognize abnormal growth across a range of gestations when local growth charts do not exist. However not all perinatal clinicians and researchers are supportive of the notion of an international standard. Using routinely collected maternity data from ten countries, a UK research group found that the average LGA rate was 20.6\% (range 5.1-27.5) and argued that IG 21 formula reflected physiological variation which blunts the standards ability to identify pathology. ${ }^{17}$ In contrast, the IG21 group compared babies born in England using local charts and documented $11 \%$ of babies born over $90^{\text {th }}$ centile compared to the IG21 rate of $19 \%$ which they believes accurately reflects the high prevalence of maternal obesity. ${ }^{18}$

In terms of maternal complications, this study noted that pregnancy-related hypertension increased as BMI category increased. These are similar to the findings of Bhattacharya et al. ${ }^{19}$ who found a three times higher risk of preeclampsia in obese women. No association between diabetes in pregnancy and BMI was found contrary to other studies, possibly because of underdiagnosis. ${ }^{20}$ We found only a few associations between perinatal complications and LGA the long-term metabolic effects including the increased risk of obesity ${ }^{21}$ and insulin resistance ${ }^{21,22}$ have possibly more important implications for the individuals and the health system in Fiji. ${ }^{9}$ Unfortunately intervention trials $^{23,24}$ in overweight and obese mothers initiated in pregnancy, such as dietary modification and increasing physical activity, have to date indicated that there is minimal benefit to pregnancy outcomes. Therefore weight changes need to be made before pregnancy. Indeed the World Health Organization (WHO) lists pregnancy planning and preconception care as one of six key strategies to reduce childhood obesity. ${ }^{25}$

\section{Limitations}

Diabetes as a complication of pregnancy did not distinguish between preexisting diabetes and although neonatal nursery admission was no higher in those LGA compared to AGA we were unable to capture neonatal complications such as hypoglycaemia. ${ }^{26}$ This study was representative of women attending the Colonial War memorial hospital for antenatal care as a similar proportion of each of the ethnic groups has been documented in other studies from this clinic ${ }^{27,28}$ but oversampled women of I-Taukei compared to the general population. ${ }^{29}$

\section{Conclusions}

Addressing health before pregnancy is going to be key if Fiji is to curb the growing trend in child and adult obesity and metabolic disease in later life. ${ }^{30}$ The World Health Organization (WHO) has recognised that one of the six key strategies to stem the rise in childhood obesity is to address maternal obesity. ${ }^{31}$

\section{Declarations}

This authors obtained ethics approval from Fiji National University and provided written consent to participation. We acknowledge the assistance of Susan Prakash, Komal Narayan and Mereoni Taufa in collection of the data. This research was supported by a staff research grant from the Fiji National University Research Committee. KB, JM, PN and IR contributed to study design. JM and PN oversaw data collection. KB and IR were involved in data analysis and the writing of the manuscript with input from JM and PN. The authors have no competing interests. 


\section{References}

1. Lopez-Arana S, Burdorf A, Avendano M. Trends in overweight by educational level in 33 low- and middle-income countries: the role of parity, age at first birth and breastfeeding. Obesity Reviews. 2013;14(10):806-817.

2. Finucane MM, Stevens GA, Cowan MJ, et al. National, regional, and global trends in body-mass index since 1980: systematic analysis of health examination surveys and epidemiological studies with 960 country-years and 1 million participants. The Lancet. 2011;377(9765):557-567.

3. Lin S, Tukana I, Linhart C, et al. Diabetes and obesity trends in Fiji over 30 years. Journal of diabetes. 2016;8(4):533-543.

4. Afshin A, Sur PJ, Fay KA, et al. Health effects of dietary risks in 195 countries, 1990-2017: a systematic analysis for the Global Burden of Disease Study 2017. The Lancet. 2019;393(10184):1958-1972.

5. Gesche J, Nilas L. Pregnancy outcome according to pre-pregnancy body mass index and gestational weight gain. International Journal of Gynecology \& Obstetrics. 2015;129(3):240-243.

6. Bhattacharya S, Campbell D, Liston W. Effect of Body Mass Index on pregnancy outcomes in nulliparous women delivering singleton babies. BMC Public Health. 2007;24(7):168.

7. Bao W, Yeung E, Tobias DK, et al. Long-term risk of type 2 diabetes mellitus in relation to BMI and weight change among women with a history of gestational diabetes mellitus: a prospective cohort study. Diabetologia. 2015;58(6):1212-1219.

8. Cheney K, Farber R, Barratt AL, et al. Population attributable fractions of perinatal outcomes for nulliparous women associated with overweight and obesity, 1990-2014. Med J Aust. 2018;208(3):119-125.

9. Drake AJ, Reynolds RM. Impact of maternal obesity on offspring obesity and cardiometabolic disease risk. Reproduction. 2010;140(3):387-398.

10. Schellong K, Schulz S, Harder T, Plagemann A. Birth Weight and Long-Term Overweight Risk: Systematic Review and a Meta-Analysis Including 643,902 Persons from 66 Studies and 26 Countries Globally. PLOS ONE. 2012;7(10):e47776.

11. Ng M, Fleming T, Robinson M, et al. Global, regional, and national prevalence of overweight and obesity in children and adults during 1980-2013: a systematic analysis for the Global Burden of Disease Study 2013. Lancet (London, England). 2014;384(9945):766-781.

12. Villar J, Ismail LC, Victora CG, et al. International standards for newborn weight, length, and head circumference by gestational age and sex: the Newborn Cross-Sectional Study of the INTERGROWTH-21st Project. The Lancet. 2014;384(9946):857-868.

13. Saugstad OD. New growth charts for newborn babies. The Lancet. 2014;384(9946):833-835.

14. World Health Organization. Body mass index (BMI) classification. 2018; http://apps.who.int/bmi/index.jsp? introPage=intro_3.html, 6/11/2018.

15. Perlow JH, Morgan MA, Montgomery D, Towers CV, Porto M. Perinatal outcome in pregnancy complicated by massive obesity. American journal of obstetrics and gynecology. 1992;167(4 Pt 1):958-962.

16. Avci ME, Sanlikan F, Celik M, Avci A, Kocaer M, Gocmen A. Effects of maternal obesity on antenatal, perinatal and neonatal outcomes. The journal of maternal-fetal \& neonatal medicine : the official journal of the European Association of Perinatal Medicine, the Federation of Asia and Oceania Perinatal Societies, the International Society of Perinatal Obstet. 2015;28(17):2080-2083.

17. Francis A, Hugh 0 , Gardosi J. Customized vs INTERGROWTH-21<sup>st</sup> standards for the assessment of birthweight and stillbirth risk at term. American Journal of Obstetrics \& Gynecology. 2018;218(2):S692-S699. 
18. Papageorghiou AT, Kennedy SH, Salomon LJ, et al. The INTERGROWTH-21 st fetal growth standards: toward the global integration of pregnancy and pediatric care. American Journal of Obstetrics and Gynecology. 2018;218(2):S630-S640.

19. Bhattacharya S, Campbell DM, Liston WA, Bhattacharya S. Effect of Body Mass Index on pregnancy outcomes in nulliparous women delivering singleton babies. BMC Public Health. 2007;7:168.

20. Chu SY, Callaghan WM, Kim SY, et al. Maternal obesity and risk of gestational diabetes mellitus. Diabetes Care. 2007;30(8):2070-2076.

21. Seidman DS, Laor A, Gale R, Stevenson DK, Danon YL. A longitudinal study of birth weight and being overweight in late adolescence. Am J Dis Child. 1991;145(7):782-785.

22. Darendeliler F, Poyrazoglu S, Sancakli O, et al. Adiponectin is an indicator of insulin resistance in non-obese prepubertal children born large for gestational age (LGA) and is affected by birth weight. Clin Endocrinol (Oxf). 2009;70(5):710-716.

23. Dodd JM, Turnbull D, McPhee AJ, et al. Antenatal lifestyle advice for women who are overweight or obese: LIMIT randomised trial. BMJ : British Medical Journal. 2014;348:g1285.

24. Poston L, Bell R, Croker $\mathrm{H}$, et al. Effect of a behavioural intervention in obese pregnant women (the UPBEAT study): a multicentre, randomised controlled trial. Lancet Diabetes Endocrinol. 2015;3(10):767-777.

25. Report of the commission on ending childhood obesity. WHO; 2016. http://apps.who.int/iris/bitstream/10665/204176/1/9789241510066_eng.pdf. Accessed 10/03/2019.

26. Groenendaal F, Elferink-Stinkens PM, Netherlands Perinatal R. Hypoglycaemia and seizures in large-forgestational-age (LGA) full-term neonates. Acta Paediatr. 2006;95(7):874-876.

27. Mahe V, Khan S, Mohammadnezhad M, Salusalu M, A. R. Obstetrics Characteristics and Adverse Outcomes of Teenage Pregnancy Cases Presented to Colonial War Memorial Hospital (CWMH) in Suva, Fiji: A Retrospective Study J Health Sci Educ. 2018;2(3):1-4.

28. Ram N, Fong J, Nusair P, Mohammadnez M, S. A. Prevalence and characteristics of caesarean section among pregnant women who delivered at the Colonial War Memorial Hospital in Suva, Fiji, 2016. Pacific Journal of Reproductive Health. 2018;1(7):384-389.

29. W. N. Report on the 2008-09 Household Income and Expenditure Survey for Fiji. Suva Fiji: Fiji Bureau of Statistics;2011.

30. Drake AJ, et al. Impact of maternal obesity on offspring obesity and cardiometabolic disease risk. Reproduction. 2010;140:387-398.

31. World Health Organization. Report of the commission on ending childhood obesity. Geneva: WHO; 10/03/2019 2016.

\section{Tables}

Table 1: Demographic factors of the study population 


\begin{tabular}{|ll|rl|}
\hline Variable & & Frequency & (Valid \%) \\
& & & \\
\hline Age group & $<25$ & 571 & $(43.6 \%)$ \\
& $25-29$ & 379 & $(28.9 \%)$ \\
& $30-34$ & 230 & $(17.6 \%)$ \\
& 35 and over & 130 & $(9.9 \%)$ \\
\hline Marital status & Married/DeFacto & 1156 & $(88.2 \%)$ \\
& Divorced or widowed & 10 & $(0.8 \%)$ \\
& Single & 145 & $(11.0 \%)$ \\
\hline Education & Primary or less & 51 & $(3.9 \%)$ \\
& Secondary & 621 & $(47.4 \%)$ \\
& Tertiary & 639 & $(48.7 \%)$ \\
\hline Ethnicity & i-Taukei & 958 & $(73.1 \%)$ \\
& Fijian Indian & 261 & $(19.9 \%)$ \\
& Fijian Rotuman & 16 & $(1.2 \%)$ \\
& Other & 75 & $(5.7 \%)$ \\
\hline BMI & Normal & 459 & $(34.8 \%)$ \\
& Overweight & 377 & $(28.6 \%)$ \\
& Obese Class 1 & 283 & $(21.5 \%)$ \\
& Obese Class 11 & 122 & $(9.3 \%)$ \\
& Obese Class 111 & 77 & $(5.8 \%)$ \\
\hline Parity & No Previous births & 472 & $(35.8 \%)$ \\
& 1 previous birth & 329 & $(25.0 \%)$ \\
& 2-4 births & 450 & $(34.1 \%)$ \\
& 5 or more & 67 & $(5.1 \%)$ \\
\hline
\end{tabular}

Table 2: $\quad$ Maternal age and pregnancy history by BMI categories

\begin{tabular}{|c|c|c|c|c|c|}
\hline Maternal Characteristic & $\begin{array}{l}\text { Normal Weight } \\
(\mathrm{n}=459)\end{array}$ & $\begin{array}{l}\text { Overweight } \\
(n=377)\end{array}$ & $\begin{array}{l}\text { Class I Obesity } \\
(n=283)\end{array}$ & $\begin{array}{l}\begin{array}{l}\text { Class II or III } \\
\text { obesity } \\
(n=199)\end{array} \\
\end{array}$ & $p$ value \\
\hline $\begin{array}{l}\text { Maternal early pregnancy } \\
\text { BMI* }\end{array}$ & $\begin{array}{l}21.84 \pm 1.82 \\
(\mathrm{n}=47)\end{array}$ & $\begin{array}{l}27.24 \pm 1.53 \\
(n=39)\end{array}$ & $\begin{array}{l}32.44 \pm 1.39 \\
(\mathrm{n}=28)\end{array}$ & $38.63 \pm 3.41(n=19)$ & 0.000 \\
\hline Maternal age (years)* & $24.85 \pm 5.09$ & $26.05 \pm 5.02$ & $27.92 \pm 5.37$ & $29.56 \pm 5.68$ & 0.000 \\
\hline Parity (\% nulliparous) & $42.9 \%$ & $36.3 \%$ & $23.6 \%$ & $17.3 \%$ & 0.000 \\
\hline PC-Hypertension (\%) & $0.7 \%$ & $1.3 \%$ & $3.2 \%$ & $3.1 \%$ & 0.030 \\
\hline PC-Diabetes mellitus (\%) & $9.2 \%$ & $7.0 \%$ & $8.6 \%$ & $6.7 \%$ & 0.574 \\
\hline
\end{tabular}

$*$ Mean \pm SD

Maternal early pregnancy BMI is only calculated for women who presented before week 10 of gestation.

$\mathrm{p}$-value for the comparison of BMI categories using t-test or $\boldsymbol{X}^{2}$.

Table 3: Delivery outcomes by BMI Categories 


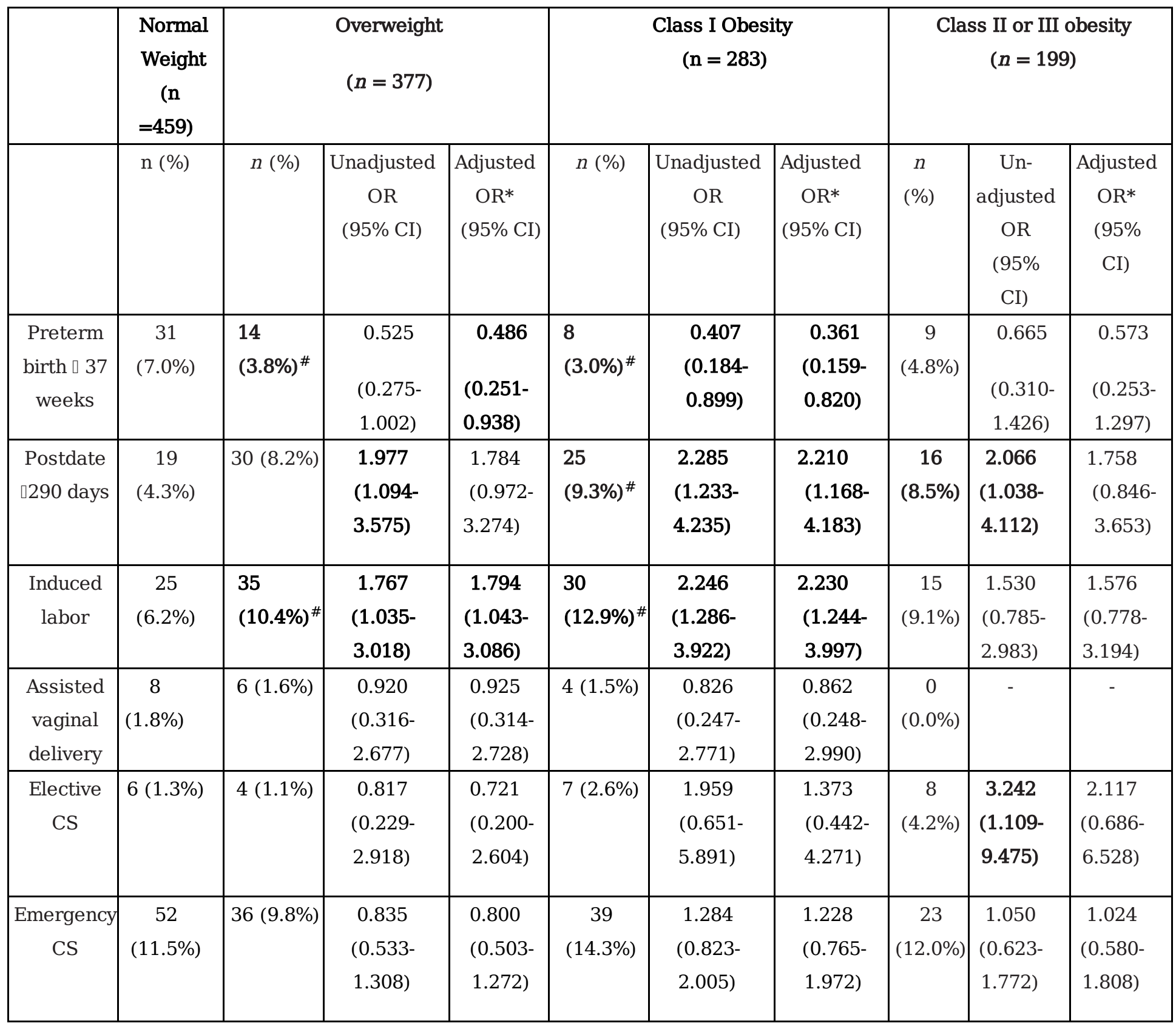

* OR adjusted for Maternal age, Parity, Hypertension and Diabetes

${ }^{\#} \mathrm{P}<0.05$

Table 4: Neonatal outcomes by BMI categories 


\begin{tabular}{|c|c|c|c|c|c|c|c|c|c|c|}
\hline & \multirow{2}{*}{$\begin{array}{c}\begin{array}{c}\text { Normal } \\
\text { Weight } \\
(\mathrm{n}=459)\end{array} \\
n(\%)\end{array}$} & \multicolumn{3}{|c|}{$\begin{array}{c}\text { Overweight } \\
(n=377)\end{array}$} & \multicolumn{3}{|c|}{$\begin{array}{l}\text { Class I Obesity } \\
\qquad(\mathrm{n}=283)\end{array}$} & \multicolumn{3}{|c|}{$\begin{array}{l}\text { Class II or III obesity } \\
\qquad(n=199)\end{array}$} \\
\hline & & $n(\%)$ & \begin{tabular}{|c} 
Un- \\
adjusted \\
OR \\
$(95 \% \mathrm{CI})$
\end{tabular} & $\begin{array}{c}\text { Adjusted } \\
\text { OR* (95\% } \\
\text { CI) }\end{array}$ & $n(\%)$ & \begin{tabular}{|c|}
\multicolumn{1}{|c|}{ Un- } \\
adjusted \\
OR \\
\\
$(95 \%$ \\
CI $)$
\end{tabular} & $\begin{array}{c}\text { Adjusted } \\
\text { OR* }(95 \% \\
\mathrm{CI})\end{array}$ & $n(\%)$ & $\begin{array}{c}\text { Un- } \\
\text { adjusted } \\
\text { OR } \\
(95 \% \mathrm{CI})\end{array}$ & $\begin{array}{c}\text { Adjusted } \\
\text { OR* } \\
(95 \% \mathrm{CI})\end{array}$ \\
\hline $\begin{array}{l}\text { Birth Weight } \square \\
\quad 2500 \mathrm{~g}\end{array}$ & $\begin{array}{c}32 \\
(7.1 \%)\end{array}$ & $\begin{array}{c}15 \\
(4.1 \%)\end{array}$ & $\begin{array}{c}0.554 \\
(0.295- \\
1.039)\end{array}$ & $\begin{array}{c}0.556 \\
(0.293- \\
1.056)\end{array}$ & $\begin{array}{c}12 \\
(4.4 \%)\end{array}$ & $\begin{array}{l}0.604 \\
(0.305- \\
1.193)\end{array}$ & $\begin{array}{l}0.603 \\
(0.296- \\
1.230)\end{array}$ & $6(3.1 \%)$ & $\begin{array}{l}0.418 \\
(0.172- \\
1.017)\end{array}$ & $\begin{array}{l}0.469 \\
(0.185- \\
1.185)\end{array}$ \\
\hline $\begin{array}{l}\text { Birth Weight } \\
\text { Below } 10^{\text {th }} \\
\text { centile }\end{array}$ & $\begin{array}{c}68 \\
(16.7 \%)\end{array}$ & $\begin{array}{c}35 \\
(10.2 \%)\end{array}$ & $\begin{array}{c}0.568 \\
(0.368- \\
0.879)\end{array}$ & $\begin{array}{c}0.607 \\
(0.389- \\
0.947)\end{array}$ & $\begin{array}{c}21 \\
(8.9 \%)^{\#}\end{array}$ & $\begin{array}{l}0.485 \\
\\
(0.289- \\
0.814)\end{array}$ & $\begin{array}{l}0.560 \\
(0.327- \\
0.960)\end{array}$ & $\begin{array}{c}10 \\
(5.9 \%)^{\#}\end{array}$ & $\begin{array}{l}0.312 \\
(0.156- \\
0.621)\end{array}$ & $\begin{array}{l}0.421 \\
(0.206- \\
0.863)\end{array}$ \\
\hline $\begin{array}{c}\text { Birth Weight } \\
4000 \mathrm{~g}\end{array}$ & $\begin{array}{c}23 \\
(5.1 \%)\end{array}$ & $\begin{array}{c}46 \\
(12.5 \%)^{\#}\end{array}$ & $\begin{array}{l}2.646 \\
(1.571- \\
4.455)\end{array}$ & $\begin{array}{c}2.30 \\
(1.35-3.91)\end{array}$ & $\begin{array}{c}53 \\
(19.6 \%)^{\#}\end{array}$ & $\begin{array}{c}4.50 \\
(2.69- \\
7.543)\end{array}$ & $\begin{array}{c}3.71 \\
(2.17-6.33) \\
\end{array}$ & $\begin{array}{c}45 \\
(23.3 \%)^{\#}\end{array}$ & $\begin{array}{c}5.632 \\
( \\
3.295- \\
9.626)\end{array}$ & $\begin{array}{l}4.43 \\
(2.52- \\
7.77)\end{array}$ \\
\hline $\begin{array}{c}\text { Birth Weight } \\
\text { Above } 90^{\text {th }} \\
\text { centile }\end{array}$ & $\begin{array}{c}45 \\
(11.1 \%)\end{array}$ & $\begin{array}{c}67 \\
(19.6 \%)\end{array}$ & $\begin{array}{l}1.960 \\
(1.302- \\
2.950)\end{array}$ & $\begin{array}{l}1.771 \\
(1.167- \\
2.687)\end{array}$ & $\begin{array}{c}57 \\
(24.1 \%)\end{array}$ & $\begin{array}{l}2.547 \\
(1.657- \\
3.915)\end{array}$ & $\begin{array}{l}2.110 \\
(1.348- \\
3.302)\end{array}$ & $\begin{array}{c}55 \\
(32.4 \%)^{\#}\end{array}$ & $\begin{array}{l}3.847 \\
(2.462- \\
6.012)\end{array}$ & $\begin{array}{l}3.053 \\
(1.907- \\
4.889)\end{array}$ \\
\hline $\begin{array}{l}\text { Low Apgar } \\
\text { score }^{\mathrm{c}}\end{array}$ & $\begin{array}{c}2 \\
(0.5 \%)\end{array}$ & $4(1.1 \%)$ & $\begin{array}{l}2.417 \\
(0.440- \\
13.27)\end{array}$ & $\begin{array}{c}2.510 \\
(0.440- \\
14.307)\end{array}$ & $4(1.5 \%)$ & $\begin{array}{l}3.258 \\
(0.593- \\
17.912) \\
\end{array}$ & $\begin{array}{c}3.482 \\
(0.591- \\
20.509) \\
\end{array}$ & $3(1.6 \%)$ & $\begin{array}{l}3.566 \\
(0.591- \\
21.517)\end{array}$ & $\begin{array}{c}4.257 \\
(0.620- \\
29.242)\end{array}$ \\
\hline $\begin{array}{l}\text { Admission in } \\
\text { NICU }\end{array}$ & $\begin{array}{c}18 \\
(4.0 \%)\end{array}$ & $\begin{array}{c}11 \\
(3.0 \%)\end{array}$ & $\begin{array}{c}0.737 \\
(0.344- \\
1.581)\end{array}$ & $\begin{array}{c}0.680 \\
(0.312- \\
1.485)\end{array}$ & $\begin{array}{c}17 \\
(6.2 \%)\end{array}$ & $\begin{array}{l}1.597 \\
(0.809- \\
3.155)\end{array}$ & $\begin{array}{l}1.257 \\
(0.608- \\
2.595)\end{array}$ & $8(4.1 \%)$ & $\begin{array}{l}1.040 \\
(0.444- \\
2.435)\end{array}$ & $\begin{array}{c}0.828 \\
(0.333- \\
2.057)\end{array}$ \\
\hline
\end{tabular}

${ }^{\text {c }}$ Apgar $<5$ at 1 minute or $<7$ at 5 minutes

* OR adjusted for Maternal age, Parity, Hypertension and Diabetes

\# $\mathrm{P}<0.05$

\section{Supplementary Files}

This is a list of supplementary files associated with this preprint. Click to download.

- STROBEchecklistv4combinedPlosMedicinelR.docx 